\title{
Vapor-Phase Ethylation of Biphenyl over MTW Zeolites
}

\author{
Shafeek Abdul Rashid Mulla, ${ }^{1, \dagger}$ Suresh B. Waghmode, ${ }^{1, \dagger \dagger}$ Seiji Watanabe, ${ }^{1}$ Hiroyoshi Maekawa, ${ }^{1}$ \\ Kenichi Komura, ${ }^{1}$ Yoshihiro Kubota, ${ }^{1,+\dagger}$ Yoshihiro Sugi, ${ }^{* 1}$ Jong-Ho Kim, ${ }^{2}$ and Gon $\mathrm{Seo}^{2}$
}

${ }^{1}$ Department of Materials Science and Technology, Faculty of Engineering, Gifu University, 1-1 Yanagido, Gifu 501-1193

${ }^{2}$ Department of Applied Chemical Engineering and The Research Institute for Catalysis, Chonnam National University, Gwangju 500-757, Korea

Received March 20, 2006; E-mail: sugi@apchem.gifu-u.ac.jp

\begin{abstract}
Vapor-phase ethylation of biphenyl (BP) with ethanol over the MTW zeolites was examined by using a fixed-bed flow reactor, and compared to the catalyses over MOR and MFI zeolites. Two types of MTW zeolites: MTW-S (small crystal) and MTW-L (large crystal) were synthesized under hydrothermal conditions. The selectivity for 4,4'-diethylbiphenyl (4,4'-DEBP) over the MTW zeolites was the highest among the other zeolites, such as MOR and MFI. The catalytic activity of MTW-S was higher than MTW-L. The selectivities for 4,4'-DEBP at $300{ }^{\circ} \mathrm{C}$ were ca. $30 \%$ for MTW-S and ca. 22\% for MTW-L among the DEBP isomers. The dealumination of the MTW zeolites enhanced the selectivity for 4,4'-DEBP although the catalytic activity was slightly decreased. In particular, the selectivity for 4,4'-DEBP over dealuminated MTW-L by steaming and subsequent refluxing in hydrochloric acid increased from 22 to $42 \%$ at $300{ }^{\circ} \mathrm{C}$. The enhancement of the selectivity for $4,4^{\prime}$-DEBP is due to the decrease in non-selective reactions at external acid sites because these sites are removed by the dealumination. The selectivities are higher than those of equilibrium mixtures, and the slimmest isomer. 4,4'-DEBP is preferentially formed due to the steric interaction of reactants and products with acidic sites in the MTW channels. Molecular modeling on the diffusion of products in the MTW channel suggests that 4,4'-DEBP isomer can diffuse most easily among DEBP isomers. 4,4'-DEBP and other isomers easily diffuse inside MOR channel; however, they cannot in the MFI channels. These results show that the formation of $4,4^{\prime}$-DEBP is the most favorable due to the diffusion and the restriction of transition state in the MTW channels.
\end{abstract}

Shape-selective alkylation of polynuclear aromatics using heterogeneous catalysts, particularly zeolite catalysts, is a promising way to prepare the slimmest isomers of aromatics which are key intermediates towards advanced materials. ${ }^{1-9}$ More specifically, the ethylation of biphenyl (BP) with ethanol produces $4,4^{\prime}$-diethylbiphenyl $\left(4,4^{\prime}\right.$-DEBP $),{ }^{6-9}$ which is a key intermediate, for the synthesis of organic compounds, such as biphenyl-4, $4^{\prime}$-dicarboxylic acid, which is an important raw material for polyester fibers, engineering plastics, liquid-crystalline polymers for electronic and mechanical devices, films with high heat resistance and strength, etc. ${ }^{13}$ Although traditional Friedel-Crafts catalysts, such as $\mathrm{AlCl}_{3}, \mathrm{SnCl}_{4}, \mathrm{BF}_{3}$, etc., are highly active for the alkylation of aromatics, they are nonselective towards the slim isomers, ${ }^{14}$ and in general, suffer from inherent problems, such as corrosiveness, high susceptibility to water, difficulty in catalyst recovery, environmental hazards, waste control after the reaction, etc. ${ }^{15}$ It is important to establish environment conscious routes to the selective synthesis of 4,4'-DEBP. Shape-selective catalyses using zeolites

\footnotetext{
$\uparrow$ Present address: Process Development Division, National Chemical Laboratory, Pune 411007, India

$\dagger$ Present address: Department of Chemistry, University of Pune, Pune 411007, India

$+\dagger \dagger$ Present address: Department of Materials Science and Engineering, Graduate School of Engineering, Yokohama National University, Yokohama 240-8501
}

as the catalyst are the most promising route for the purpose.

Although several attempts have been made towards the ethylation of BP, there are few literatures on the selective formation of 4,4'-DEBP. ${ }^{6-11}$ Takeuchi et al. described the selective formation of 4,4'-DEBP in the transethylation of BP with polyethylbenzenes over zeolites such as FAU, MOR, etc. ${ }^{10,11}$ They suggested that selective formation of $4,4^{\prime}$-DEBP was not due to shape-selective catalysis by zeolites, but to the kinetic control at low temperatures. We also found that $4,4^{\prime}$-DEBP was easily isomerized to 3,4'- and 3,3'-isomers over the FAU zeolites, and concluded that $4,4^{\prime}$-DEBP is formed shape-selectively by the transethylation of BP with diethylbenzenes; however, subsequent isomerization of $4,4^{\prime}$-DEBP lowers the selectivity for $4,4^{\prime}$-DEBP. ${ }^{12}$

We previously described that the ethylation of BP over the MOR zeolites afforded the selectivity for 4,4'-DEBP in less than $10 \%$, and that they accompanied the formation of higher ethylates, such as triethylbiphenyls (TriEBP), tetraethylbiphenyls (TetraEBP), and polyethylbiphenyls (PEBP). From the detailed analysis of bulk and encapsulated products, we concluded that 4,4'-DEBP was formed preferentially by shapeselective catalysis over the MOR zeolites. However, the resulting slimmest $4,4^{\prime}$-DEBP disappeared preferentially because it consumed to form PEBP isomers. ${ }^{6-9}$ The MOR channels $(0.67 \times 0.70 \mathrm{~nm})^{16}$ are too wide to restrict the consumption of $4,4^{\prime}$-DEBP, which formed inside channels by shape-selective catalysis. A zeolite with narrower pores and channels is 
essential to achieve the high selectivity for 4,4'-DEBP. Among the zeolites, the MTW zeolite is a candidate for the catalysis, because it has the straight channels with pore mouth of $0.56 \times$ $0.6 \mathrm{~nm}^{16}$

In the present work, we examined the vapor-phase ethylation of BP with ethanol over MTW, MOR, and MFI zeolites in order to establish the shape-selective synthesis of $4,4^{\prime}$ DEBP. The fitting of diffusion of DEBP isomers inside channel of the zeolites (MTW, MOR, and MFI) were also examined by molecular modeling.

\section{Experimental}

Catalysts. The MTW zeolites were synthesized by two methods: tetraethylammonium bromide was used as a structure-directing agent (SDA) to afford small crystal MTW zeolite (MTW-S), ${ }^{17}$ and triethylmethylammonium bromide was used to give large crystal MTW zeolite (MTW-L). ${ }^{18}$ Calcined MTW samples were converted to $\mathrm{H}$-form by using $20 \mathrm{~mL}$ of $1 \mathrm{M}$ solution of ammonium nitrate per gram of catalyst for $12 \mathrm{~h}$ at $80^{\circ} \mathrm{C}$. This procedure was repeated three times. MFI $\left(\mathrm{SiO}_{2} / \mathrm{Al}_{2} \mathrm{O}_{3}=190\right.$; HSZ870NHA, $\mathrm{NH}_{4}$ form $)$ and $\mathrm{MOR}\left(\mathrm{SiO}_{2} / \mathrm{Al}_{2} \mathrm{O}_{3}=206\right.$; TSZ690HOA) zeolites was obtained from Tosoh Corporation, Tokyo. All catalysts were calcined prior to use at $550^{\circ} \mathrm{C}$ for $7 \mathrm{~h}$.

The dealumination of MTW-S and MTW-L was carried out by using $20 \mathrm{~mL}$ of $1 \mathrm{M}$ solution of ethylenediaminetetraacetic acid (EDTA) per gram of zeolite for $12 \mathrm{~h}$ at $80^{\circ} \mathrm{C}$. After the dealumination, zeolites were calcined at $550{ }^{\circ} \mathrm{C}$ for $7 \mathrm{~h}$. The abbreviation of the dealuminated MTW is MTW-S1 and MTW-L1, from MTW-S and MTW-L, respectively. MTW-L was also dealuminated by steaming at $600{ }^{\circ} \mathrm{C}$ for $12 \mathrm{~h}$ and subsequent refluxing in $1 \mathrm{M}$ hydrochloric acid for $12 \mathrm{~h}$. The sample is abbreviated as MTW-L2.

Ethylation of BP. Vapor-phase ethylation of BP with ethanol was carried out in a fixed bed, continuous, tubular down flow, Pyrex glass reactor of $25 \mathrm{~cm}$ length and $1 \mathrm{~cm}$ internal diameter in an electrically heated furnace. Fresh catalyst $(1 \mathrm{~g}$; sieved to mesh size around 30) was placed in the middle of the reactor, and sandwiched between glass wool plugs. The glass reactor equipped with pre-heater assembly kept at $225^{\circ} \mathrm{C}$ was heated to requisite temperature. Prior to reaction, the catalyst was activated in $\mathrm{O}_{2}$ gas flow $\left(50 \mathrm{~mL} \mathrm{~min}^{-1}\right)$ at $580^{\circ} \mathrm{C}$ for $6 \mathrm{~h}$. Reaction was carried out in a nitrogen flow $\left(10 \mathrm{~mL} \mathrm{~min}^{-1}\right)$ at atmospheric pressure. Feed was composed of 1:5:5.5 molar ratio of $\mathrm{BP}$, ethanol, and cyclohexane $(\mathrm{CH})(\mathrm{BP}: \mathrm{EtOH}: \mathrm{CH})$. The products were passed through a watercooled condenser, and collected time-to-time after an interval of $2 \mathrm{~h}$. The catalyst used for the ethylation was regenerated in an oxygen flow $\left(50 \mathrm{~mL} \mathrm{~min}^{-1}\right)$ at $580^{\circ} \mathrm{C}$ for $6 \mathrm{~h}$ and reused. The products were identified using GC-MS (QP 5000, Shimadzu Corporation, Kyoto) and analyzed by a Shimadzu Model 18A chromatograph with FID (Column: Ultra-1 capillary column, $25 \mathrm{~m} \times 0.3 \mathrm{~mm}$; Agilent Technologies, CA, U.S.A.).

The conversion of BP and the yield of the products were calculated based on the amount of BP introduced. The selectivity for each isomer of ethylbiphenyls (EBP) and diethylbiphenyls (DEBP) is expressed as percentages of each EBP and DEBP isomer among total EBP and DEBP isomers.

$$
\begin{aligned}
& \text { Selectivity for a DEBP (EBP) isomer }(\%) \\
& =\frac{\text { Each DEBP }(\mathrm{EBP}) \text { isomer }(\mathrm{mol})}{\mathrm{DEBP}(\mathrm{EBP}) \text { isomers }(\mathrm{mol})} \times 100
\end{aligned}
$$

Estimation of Equilibrium Mixtures of DEBP Isomers.
Table 1. Estimation of Equilibrium Mixture of DEBP Isomers ${ }^{\text {a) }}$

\begin{tabular}{cccccc}
\hline Period & \multicolumn{5}{c}{ DEBP composition/\% } \\
\cline { 2 - 6 }$/ \mathrm{h}$ & $3,3^{\prime}-$ & $3,4^{\prime}-$ & $4,4^{\prime}-$ & $3,5-$ & others \\
\hline 0 & 0 & 0 & 100 & 0 & 0 \\
$1 / 3$ & 20 & 47 & 12 & 14 & 8 \\
1 & 19 & 53 & 12 & 11 & 5 \\
2 & 18 & 55 & 13 & 10 & 4 \\
3 & 18 & 56 & 12 & 10 & 4 \\
\hline
\end{tabular}

a) Reaction conditions: 4,4'-DEBP, $10 \mathrm{mmol}$; H-FAU, $0.5 \mathrm{~g}$; reaction temperature, $300{ }^{\circ} \mathrm{C}$.

4,4'-DEBP was heated in contact with FAU $\left(\mathrm{SiO}_{2} / \mathrm{Al}_{2} \mathrm{O}_{3}=11\right.$, HSZ-350HUA, Tosoh Corporation) at $300{ }^{\circ} \mathrm{C}$ for a long period until no change of the composition of DEBP occurred. Typical results are given in Table 1 .

Characterization of Catalysts. The phase purity and the crystallinity of the zeolites were determined by using a powder $\mathrm{X}$-ray diffractometer (Shimadzu XRD-6000) with $\mathrm{Cu} \mathrm{K} \alpha$ radiation $(\lambda=0.15418 \mathrm{~nm})$. Elemental analysis was performed using inductively coupled plasma spectroscopy (JICP-PS-1000UV, Leeman Labs Inc., NH, U.S.A.). The crystal size and the morphology of the sample were observed by scanning electron microscopy using an XL30 microscope (Philips, the Netherlands). Nitrogen adsorption measurements were carried out on a BELSORP 28SA (BEL Japan Inc., Osaka). Acidity measurements were performed by temperature-programmed desorption of ammonia $\left(\mathrm{NH}_{3}-\mathrm{TPD}\right)$ on a TPD-66 apparatus (BEL Japan). The adsorption of $o$-xylene was performed by gravimetric method with its vapor $(0.48 \mathrm{kPa})$ using highly sensitive quartz microbalance at $120^{\circ} \mathrm{C}$ after the evacuation at $550^{\circ} \mathrm{C}$. Initial rate of adsorption was calculated based on the adsorption during the initial $20 \mathrm{~s}$.

Modeling of the Products inside the Channels. Computational studies were carried out using Material Studio's (MS) supplied by Accelrys Inc., U.K. Molecular graphics (MG) displays were obtained from an MS system using a Dell 8250 computer.

Quantum chemical calculations for full geometry optimization of total energies of organic molecules were done using the density functional theory (DFT) with Level 6-311G(d,p) basis sets by using Gaussian 03 software. ${ }^{19}$ As the exchange functional, Becke's hybrid exchange B3 was used as correlation functionals, the LeeYang-Parr non-local functional (LYP). The extents of the molecule in space were calculated for the energetically favorable conformation and their sizes and shapes were analyzed. The dimensions of molecules in three-dimensional space were measured according to the procedure detailed elsewhere. ${ }^{20}$ The three largest dimensions $(a \times b \times c)$ of BP; 2,4'-, 2,4-, 3,3'-, 3, $4^{\prime}-$, and 4,4'DEBP in mutually perpendicular directions are given in Table 2.

Qualitative structure fitting of the molecules inside the channels

Table 2. Kinetic Dimensions and Potential Energies of BP and DEBP Isomers

\begin{tabular}{lcc}
\hline DEBP & $\begin{array}{c}\text { Dimensions }(a \times b \times c) \\
/ \mathrm{nm}\end{array}$ & $\begin{array}{c}\text { Potential energy } \\
/ \text { a.u. }\end{array}$ \\
\hline BP & $0.52 \times 0.52 \times 1.08$ & - \\
$2,4^{\prime}-$ & $0.5 \times 0.71 \times 1.02$ & -614.3379 \\
$2,4-$ & $0.54 \times 0.75 \times 1.02$ & -615.0338 \\
$3,3^{\prime}-$ & $0.64 \times 0.66 \times 1.10$ & -615.0363 \\
$3,4^{\prime}-$ & $0.57 \times 0.72 \times 1.22$ & -615.0366 \\
$4,4^{\prime}-$ & $0.52 \times 0.52 \times 1.44$ & -615.0365 \\
\hline
\end{tabular}


Table 3. Crystal Characteristics and the Dimensions of the Simulation Boxes for Zeolites

\begin{tabular}{|c|c|c|c|c|c|c|c|}
\hline Zeolite & Symmetry & $\begin{array}{c}\text { Unit-cell } \\
\text { composition }\end{array}$ & $\begin{array}{c}a \\
/ \mathrm{nm}\end{array}$ & $\begin{array}{c}b \\
/ \mathrm{nm}\end{array}$ & $\begin{array}{c}c \\
/ \mathrm{nm}\end{array}$ & $\begin{array}{l}\text { Pore } \\
\text { diameter } \\
\text { /nm }\end{array}$ & $\begin{array}{c}\text { Number of } \\
\text { unit-cells in } \\
\text { simulation box }\end{array}$ \\
\hline MTW & Orthorhombic & $\left(\mathrm{SiO}_{2}\right)_{48}$ & 2.4863 & 0.5012 & 2.0326 & $0.56 \times 0.56$ & $2 \times 2 \times 8$ \\
\hline MOR & Orthorhombic & $\left(\mathrm{SiO}_{2}\right)_{48}$ & 1.8094 & 2.0516 & 0.7524 & $0.65 \times 0.70$ & $2 \times 2 \times 8$ \\
\hline MFI & Orthorhombic & $\left(\mathrm{SiO}_{2}\right)_{96}$ & 2.0022 & 1.9899 & 1.3383 & $0.51 \times 0.56$ & $2 \times 4 \times 2$ \\
\hline
\end{tabular}

Table 4. Physicochemical Properties of the MTW Zeolites

\begin{tabular}{lccccc}
\hline \multirow{2}{*}{ Zeolite } & $\mathrm{SiO}_{2} / \mathrm{Al}_{2} \mathrm{O}_{3}$ & $\begin{array}{c}\text { Pore } \\
\text { volume } \\
/ \mathrm{cm}^{3} \mathrm{~g}^{-1}\end{array}$ & $\begin{array}{c}\mathrm{BET} \\
\text { surface area } \\
/ \mathrm{m}^{2} \mathrm{~g}^{-1}\end{array}$ & $\begin{array}{c}\text { Peak temp } \\
/{ }^{\circ} \mathrm{C}\end{array}$ & $\begin{array}{c}\mathrm{NH}_{3} \text {-TPD } \\
/ \mathrm{mmol} \mathrm{g}^{-1}\end{array}$ \\
\hline MTW-S & 128 & 0.063 & 182 & 317 & 0.186 \\
MTW-S1 & 145 & 0.047 & 177 & 314 & 0.110 \\
MTW-L & 102 & 0.093 & 209 & 320 & 0.140 \\
MTW-L1 & 122 & 0.067 & 146 & 324 & 0.125 \\
MTW-L2 & 136 & 0.088 & 212 & 312 & 0.106 \\
MOR & 203 & 0.198 & 597 & 385 & 0.193 \\
MFI & 190 & 0.082 & 394 & 335 & 0.094 \\
\hline
\end{tabular}

of MTW, MOR, and MFI zeolites were studied by Molecular Graphics (MG) and compared the dimensions of the molecules with pore diameter. The zeolite lattices were generated from crystallographic data reported in the literatures. ${ }^{21-23}$ Further, the chemical interactions between the zeolite (host) and the organic molecules (guests) were studied using energy minimization calculations to understand the adsorption sites and diffusion characteristics of BP and DEBP isomers. The simulation box contained the zeolite generated from its crystal structure and the actual dimensions of the simulation are shown in Table 3. The size of the simulation boxes were chosen in such a way that the symmetry along the channel direction is taken care of and the box is just large enough in the other two directions to take care of the non-bonded interactions, which took a cut-off distance of $0.95 \mathrm{~nm}$. The diffusion energy profiles symmetrically repeat themselves in each unitcell, indicating the validity of the simulation box size, potential parameters, and energy minimization calculation procedures. The calculations were performed following well established forced diffusion procedures.

The force field energy minimization calculations were done with the Discover program, using consistent valence force field (CVFF) by Hagler et al. ${ }^{24}$ and the parameters were obtained from the reports of Dauber-Osguthorpe et al. ${ }^{25}$ The detailed methodology is reported elsewhere. ${ }^{20}$

For the calculation of the diffusion of the DEBP isomers in the channels of MTW, MOR, and MFI zeolites, the molecules were forced to diffuse in regular steps of $0.2 \mathrm{~nm}$ along the diffusion path within the channel. At each point, a strong harmonic potential was used to constrain the molecule to lie at a fixed distance from the initial position while the energetically favorable conformation and orientation of the molecule were derived by varying the internal degrees of freedom as well as non-bonding interaction of the molecule with the zeolite framework. The interaction energy at each point was calculated using Eq. 2:

$$
\begin{aligned}
& \text { Interaction Energy } \\
& \quad=E_{\text {zeolite:molecule complex }}-\left(E_{\text {zeolite }}+E_{\text {molecule }}\right) .
\end{aligned}
$$

Thus, the diffusion energy profile is a graph showing the variation of interaction energy between a single molecule and the zeolite framework as the molecule diffuses within the channel of the zeolite. The difference in energy between the most favorable and most unfavorable sites in the diffusion energy profile gives the diffusion energy barrier for self-diffusivity. During these calculations of the interaction energy, the atoms in the zeolite lattice were fixed at their crystallographically determined geometries, whereas the guest molecules were flexible. The influence of the presence of more molecules on the diffusivity (mutual effect) and the influence of temperature are not considered here. In view of these approximations, suitable care was taken to interpret the results.

\section{Results and Discussion}

Properties of the MTW Zeolites. Typical properties of zeolites used in this study are shown in Table 4. Figure 1 shows the XRD patterns of the MTW zeolites synthesized by the two procedures. They have high crystallinity without any impure phase although the crystallinity of MTW-L was higher than that of MTW-S. SEM images in Fig. 2 show that MTW-L had a particle size larger than MTW-S: $>1 \mu \mathrm{m}$ for MTW-S and $7 \mu \mathrm{m}$ for MTW-L. Both MTW zeolites have almost the same $\mathrm{SiO}_{2} / \mathrm{Al}_{2} \mathrm{O}_{3}$ ratio. BET surfaces of MTW-S and MTW-L were nearly the same, although MTW-L has larger pore volume than MTW-S.

The dealumination of MTW-S with EDTA was faster than that of MTW-L because EDTA can easily access aluminum in the zeolites. The $\mathrm{SiO}_{2} / \mathrm{Al}_{2} \mathrm{O}_{3}$ ratio of the dealuminated MTW was not directly correlated to the acid amount (Table 4, see also Fig. 3). The acid amount was decreased for MTW-L1 by dealumination with EDTA; however, MTW-L1 has almost the same amount of acid sites compared to original MTW-L. The dealumination of MTW-L by steaming and refluxing in $1 \mathrm{M}$ hydrochloric acid gave MTW-L2 with a higher $\mathrm{SiO}_{2} /$ $\mathrm{Al}_{2} \mathrm{O}_{3}$ ratio than that from EDTA treatment. These results show that MTW-S was dealuminated more easily than MTWL, which is due to the higher crystallinity of MTW-L than that of MTW-S judging from XRD patterns. The crystallinities of MTW-L were still higher than that of MTW-S even after the dealumination. BET surface area and pore volume did 


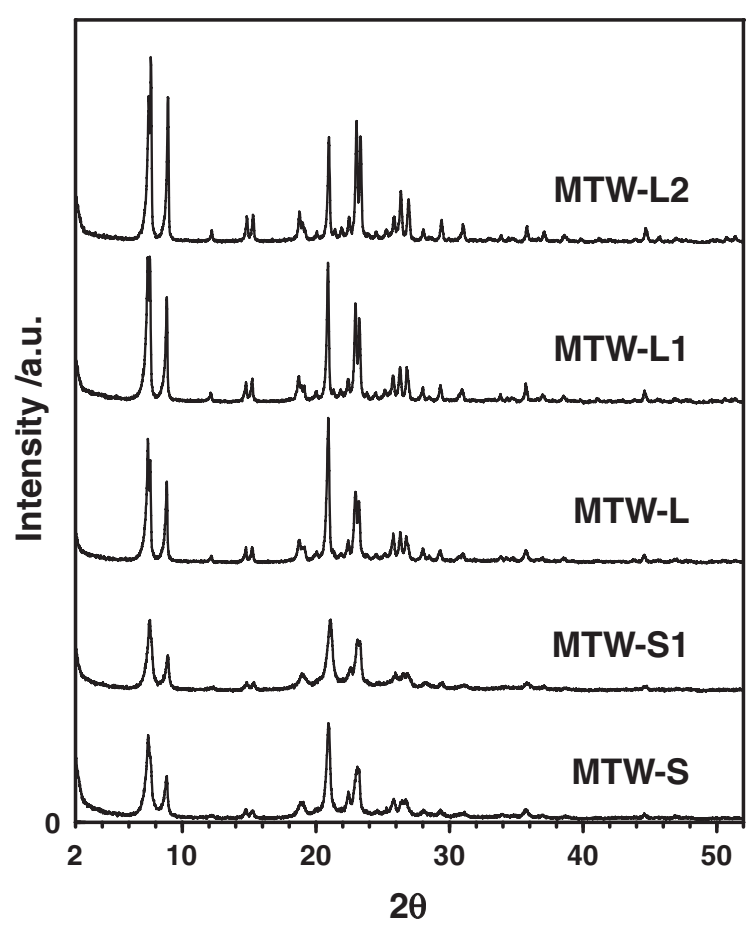

Fig. 1. XRD patterns of the MTW zeolites.

(a)

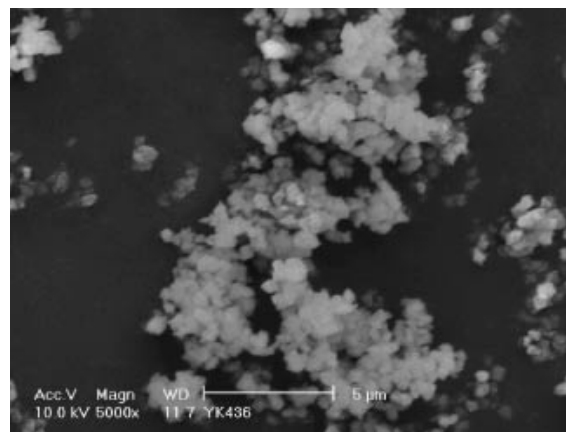

(b)

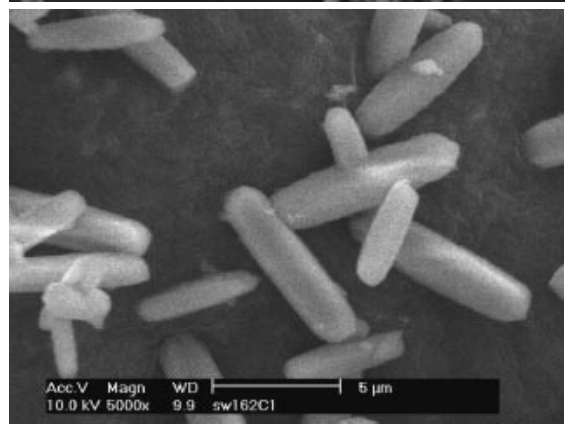

Fig. 2. SEM images of the MTW zeolites; a) MTW-S and b) MTW-L.

not correlate to the dealumination of MTW (Table 4).

Temperature-programmed desorption of $\mathrm{NH}_{3}\left(\mathrm{NH}_{3}-\mathrm{TPD}\right)$ of MTW-S and MTW-L, and their dealuminated samples gave typical profiles as in Fig. 3. All MTW samples have two peaks, $l$-peak and $h$-peak. Table 4 also shows peak temperatures of the major desorption peak ( $h$-peak), which are correlated to acid strength, and the acid amounts, which are calculated from area of $h$-peak. All dealuminated MTW zeolites have similar acid strength because they have similar peak temperatures

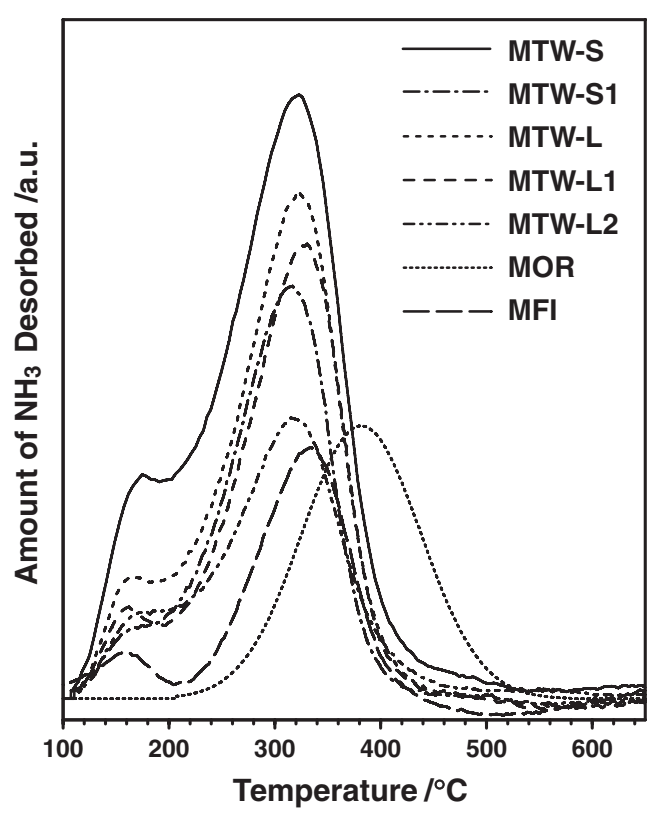

Fig. 3. $\mathrm{NH}_{3}$ TPD profiles of the MTW zeolites.

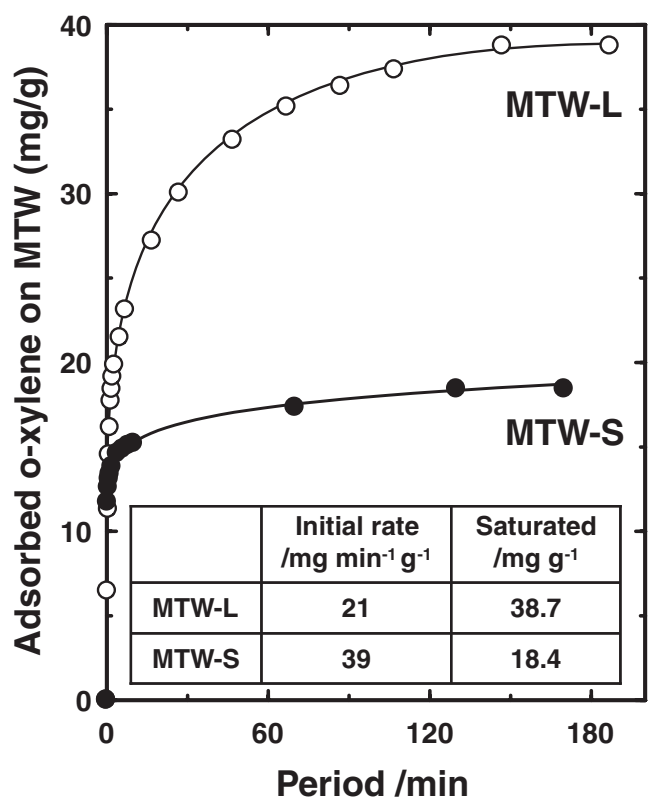

Fig. 4. Adsorption of $o$-xylene over the MTW zeolites at $120^{\circ} \mathrm{C}$.

even after dealumination. These results mean that the acid strength did not change after the dealumination. However, the acid amount decreased for all MTW zeolites by the dealumination judging from the peak area. The acid amounts of MTW-S1, dealuminated by EDTA, decreased significantly compared to original MTW-S. The decrease in the acid amount of MTW-L was small when EDTA was used; however, a significant decrease in the acid amount was observed when MTW-L was dealuminated by steaming and refluxing with $1 \mathrm{M}$ hydrochloric acid. As seen from Fig. 3, the MTW zeolites have a weaker acid strength than MOR zeolites; however, it is the same as MFI zeolites.

Figure 4 shows $o$-xylene adsorption on the MTW zeolites. The initial adsorption rate of MTW-S was very rapid com- 


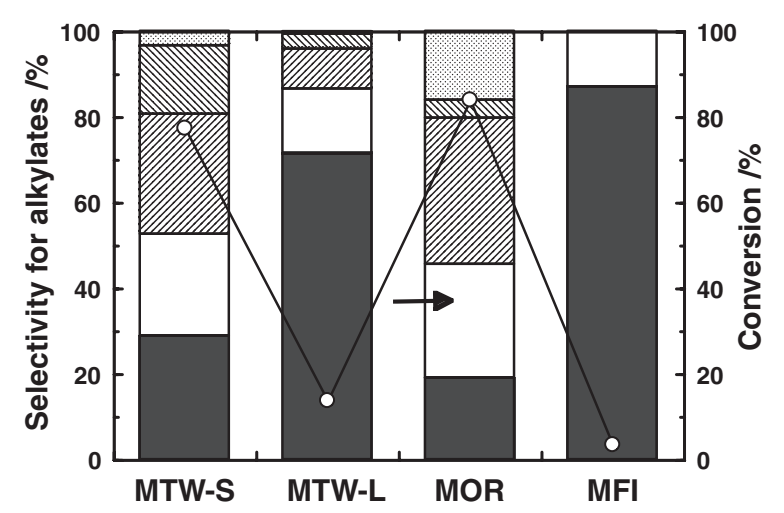

Fig. 5. The influence of the zeolites on the catalytic activity and the selectivity for ethylated products: Reaction conditions: temperature, $300^{\circ} \mathrm{C}$; feed, 1:5:5.5 (BP:EtOH:CH (mole ratio)); WHSV, 8/h. Data were taken at $6 \mathrm{~h}$ after starting. Legends: $\bigcirc$ : Conversion. $\square$ : EBP; $\square$ : DEBP; प: TriEBP; $\mathbb{\mathbb { Q }}$ : TetraEBP; 娄: PEBP.

pared to MTW-L. However, the amount of adsorption on MTW-S after saturation was half amount of MTW-L. The differences are due to the differences of crystallinity of the zeolites, because the surface areas of both zeolites were similar as seen in Table 2. XRD patterns also support the results because MTW-L has much higher crystallinity than MTW-S.

The adsorption of organic molecule on zeolites is influenced by the properties of the zeolites, such as zeolite type, crystal sizes, crystallinity, etc. The number of pore mouths in small crystals is larger than that in large crystals, and large crystals have longer channels The rapid adsorption of $o$-xylene on MTW-S at the initial stage should be due to the larger number of channels in MTW-S and/or to short channel length, and a large amount of saturated $o$-xylene adsorption on MTW-L should be due to its long channel length and higher crystallinity in comparison with MTW-S.

Influences of the MTW Zeolites on the Ethylation of BP. Figure 5 shows the ethylation of BP over MTW, MOR, and MFI zeolites at $300^{\circ} \mathrm{C}$. The activity for the MOR zeolite was the highest among zeolites in this study; however, the MFI zeolite had very low activity. The MTW zeolites had intermediate activities between MOR and MFI zeolites. These results reflect the influences of the pore mouth of the zeolites on the activity. Our previous studies shows that $4,4^{\prime}$-DEBP was formed preferentially from 4-EBP over the MOR zeolites. ${ }^{8,9}$ However, $4,4^{\prime}$-DEBP, which the most reactive among their isomers, were preferentially consumed to give TriEBP, TetraEBP, and PEBP because the MOR channels are wide enough for the further alkylation of DEBP isomers. The activity of MTW-L was lower than that of MTW-S, and principal products were EBP and DEBP; however, MTW-S gave high activities to yield principally DEBP, TriEBP, TetraEBP, and PEBP. The selectivity for these higher ethylates over MTW$S$ was lower than that of the MOR zeolite. The ethylation of BP over the MFI zeolites principally occurred at external acid sites to resulting in the low catalytic activity because their channels are too small for BP to enter and for BP and products to accommodate.

Significant differences in catalytic activity are observed between two types of MTW zeolites, i.e., MTW-S had much

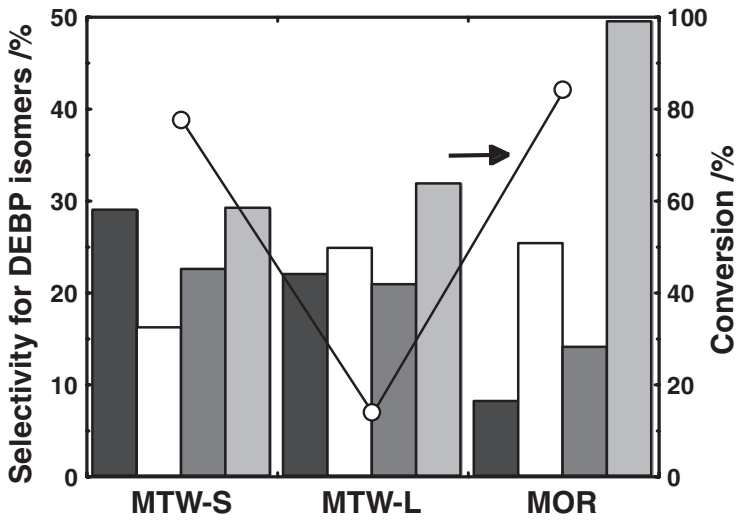

Fig. 6. The influence of the zeolites on the selectivity for DEBP isomers. Reaction conditions: see Fig. 5. Legends:

$\bigcirc:$ Conversion. $\square: 4,4^{\prime}-; \square: 3,4^{\prime}-; \square: 3,3^{\prime}-; \square: 2, x^{\prime}-$.

higher activity than MTW-L. These differences did not reflect the acidity of the zeolites because both catalysts had similar aluminum amount as in Table 4. The low activity of MTW$\mathrm{L}$ is due to severe coke-deposition as discussed below.

The selectivities for EBP and DEBP over MTW-S were 20$30 \%$, respectively, and other products were higher ethylates, TriEBP, TetraEBP, and PEBP. However, MTW-L gave principally EBP, and the selectivities for DEBP and higher ethylates were less than $10 \%$. The low selectivity for DEBP over MTW$\mathrm{L}$ should be due to its low activity.

Figure 6 shows the selectivity for DEBP isomers over MTW-S, MTW-L, and MOR zeolites in the ethylation of BP at $300^{\circ} \mathrm{C}$. The selectivities for $4,4^{\prime}$-DEBP isomer over MTW$\mathrm{S}$ and MTW-L were 28 and $22 \%$ at $300^{\circ} \mathrm{C}$, respectively. The other principal DEBP isomers are $3,4^{\prime}-$ and $3,3^{\prime}$-DEBP in addition to $2, x^{\prime}$-DEBP $\left(2,2^{\prime}-, 2,3^{\prime}-\right.$, and $2,4^{\prime}$-DEBP $)$. The selectivities for $4,4^{\prime}$-DEBP over the MTW zeolites are higher than those with the MOR zeolite as previously described. ${ }^{6-8}$ The lower selectivity over MTW-L compared to that of MTW-S is due to the small number of pore mouths and the severe coke-deposition, i.e., the choking of the channels of MTW-L should be higher than that of MTW-S (see below). These results suggest that acid sites inside channels of MTW-L was choked by the coke-formation, and that the external acid sites, which are still active in spite of choking of the MTW-L pore, catalyze the non-selective ethylation to result in low selectivity for $4,4^{\prime}$-DEBP.

The catalytic activity and the selectivity for $4,4^{\prime}$-DEBP over the MTW zeolites were influenced by their crystal sizes as discussed above. The number of pore mouths of small crystals should be larger than that of large crystals, and large crystals have longer channels. The rapid adsorption of $o$-xylene on MTW-S at the initial stage should be due to the larger numbers of pore mouths of MTW-S and/or to short channel length, and the large adsorption of $o$-xylene on MTW-L shows its long channel length in comparison with MTW-S. These features correspond to the difference in catalytic performances between MTW-L and MTW-S. Higher catalytic activity for MTW-S should be due to a large numbers of pore mouths with short channels. On the other hand, the decrease in the catalytic activity of MTW-L is due to severe coke-deposition.

Dealumination of the MTW Zeolites. The deactivation of 


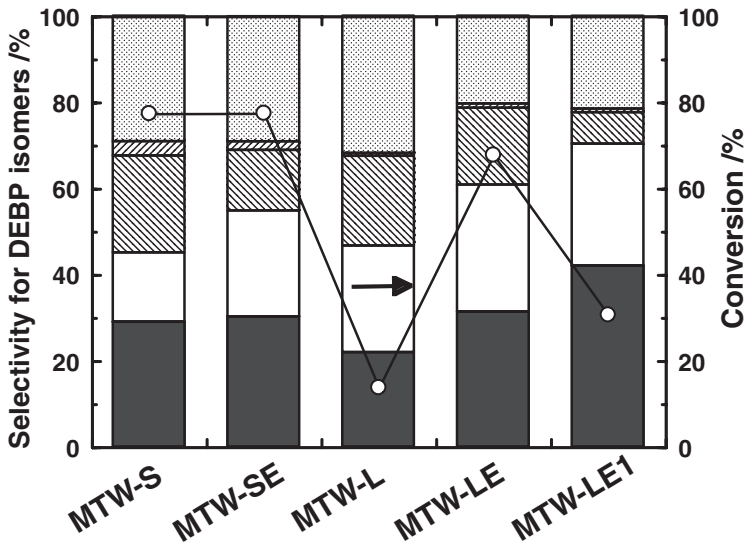

Fig. 7. The Influence of the dealumination of the MTW zeolites on the ethylated products. Reaction conditions and Legends: see Fig. 5.

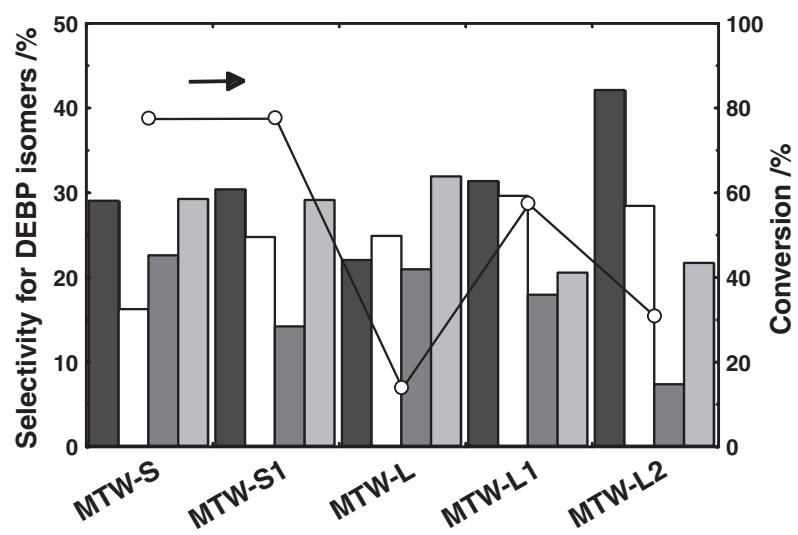

Fig. 8. Influences of the dealumination of the MTW zeolites on the selectivity for DEBP isomers: Reaction conditions and Legends: see Fig. 6.

external acid sites is necessary to improve the catalytic activity and the selectivity for $4,4^{\prime}$-DEBP by the preventing the isomerization of $4,4^{\prime}$-DEBP. Dealumination is an effective method for the removal of acid sites, particularly from external surfaces.

Figure 7 shows that catalytic activity of dealuminated MTW zeolites in the ethylation of BP at $300^{\circ} \mathrm{C}$. MTW-S was catalytically more active than MTW-L. The dealumination enhanced catalytic activity of MTW-L; however, the activity was not changed by the dealumination of MTW-S.

Figure 7 also shows the composition of ethylated biphenyls over dealuminated MTW zeolites in the ethylation of BP at $300^{\circ} \mathrm{C}$. Dealuminated MTW-S and MTW-L showed slightly different catalytic behaviors. Although the formation of TriEBP and its higher ethylates was enhanced on MTW-S, the conversion of BP did not change after dealumination. These results are due to further ethylation of EBP isomers to higher ethylates. The formation of higher ethylates was also enhanced over MTW-L1 and MTW-L2 regardless of the dealumination method, although MTW-L2 was less active compared to MTW-L1. The enhancement for MTW-L was caused by a decrease in coke-deposition (see below).

Figure 8 shows the influence of the dealumination of the

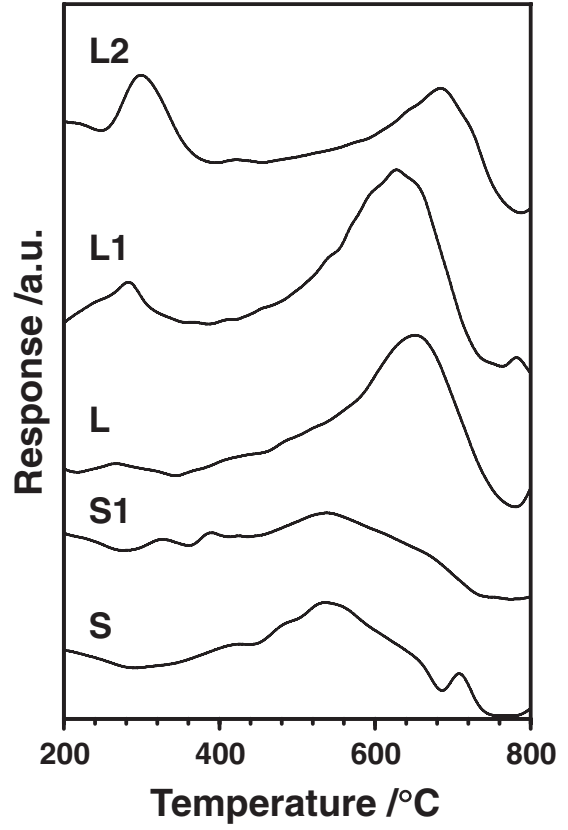

Fig. 9. TG profiles of the catalysts used for the ethylation.

Reaction conditions: see Fig. 5.

MTW zeolites on the selectivity for DEBP isomers at $300{ }^{\circ} \mathrm{C}$. The selectivity for 4,4'-DEBP over MTW-S was around $30 \%$, and did not change after dealumination by EDTA treatment. It is due to the further ethylation of the EBP isomers to higher ethylates as discussed for the MOR zeolites in previous papers. $^{7-9}$ On the other hand, an increase in the selectivity for 4,4'-DEBP was observed over MTW-L1 and MTW-L2: $31 \%$ for MTW-L1 and $42 \%$ for MTW-L2. The dealumination by steaming and refluxing in hydrochloric acid was more effective than the treatment with EDTA although the activity of the former was less. The improvement in the selectivity for $4,4^{\prime}$-DEBP was due to a decrease in non-shape selective formation of DEBP isomers and in the isomerization of $4,4^{\prime}$ DEBP by the dealumination. From these results, the selectivities for 4,4'-DEBP of MTW-L2 are the most plausible selectivities for the MTW structure. Further investigations on the liquid-phase ethylation of BP are in progress to elucidate the shape-selective nature of the MTW zeolites.

The selectivities for 4,4'-DEBP over dealuminated MTW zeolites are higher than those of equilibrium mixtures shown in Table 1. The MTW channels have the shape-selective characteristics for the formation of $4,4^{\prime}$-DEBP, and the slimmest isomer, $4,4^{\prime}$-DEBP is preferentially formed due to the steric interaction of reactants and products with acidic sites in the MTW channels.

Figure 9 shows coke formation on catalysts used for the ethylation of BP at $400-700^{\circ} \mathrm{C}$ by thermogravimetric analysis. These peaks are due to the combustion of coke deposited during the ethylation of BP. The amount of coke decreased as a result of dealumination from $3.3 \%$ for MTW-S to $2.4 \%$ for MTW-S1. No significant decrease in the coke-deposition for MTW-L1 was observed by EDTA treatment (MTW-L: $5.0 \%$ and MTW-L1 4.3\%). However, coke-deposition over MTW-L2 (2.8\%) was about a half of original MTW-L. These results suggest that steaming and refluxing in hydrochloric acid 


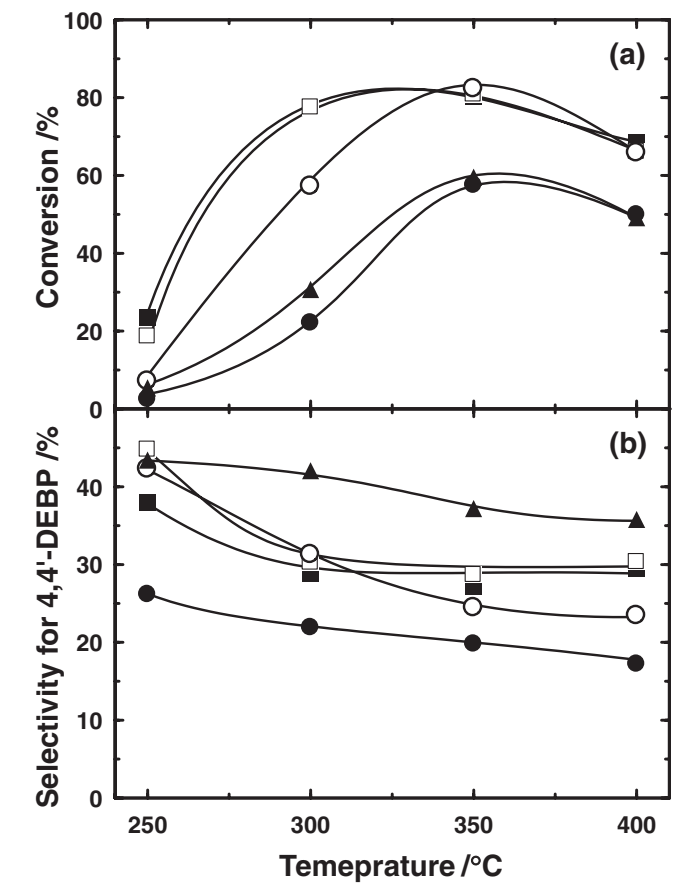

Fig. 10. Influences of reaction temperature on catalytic activity and selectivity for DEBP isomers in the ethylation of BP over dealuminated MTW zeolites. (a): Conversion of BP; (b) Selectivity for 4,4'-DEBP. Reaction conditions: catalyst, $1 \mathrm{~g}$; feed, 1:5:5.5 (BP:EtOH:CH (molar ratio)); WHSV, 8/h. Data were taken at $6 \mathrm{~h}$ after starting. Legends: $\square:$ MTW-S; $\square$ : MTW-S1; ๑: MTW-L; $\bigcirc:$ MTWL1; $\boldsymbol{\Delta}$, MTW-L2.

was more effective in dealumination than the EDTA treatment was. The selectivity for $4,4^{\prime}$-DEBP increased after the dealumination of MTW-L as discussed above. The increase is due to the decrease in the acid sites and to the decrease in cokedeposition. The coke-deposition at the acid sites on the MTW zeolites, which are remained after dealumination, cannot be prevented during the catalysis. Particularly, the formation of TriEBP and TetraEBP over MTW-L increased due to dealumination. On the other hand, no significant improvement in the selectivity for 4,4'-DEBP was observed for MTW-S, which is due to the preferential ethylation of $4,4^{\prime}$-DEBP to higher ethylates.

Influences of Reaction Temperature. Figure 10 shows the influence of reaction temperature on the activity and the selectivity for $4,4^{\prime}$-DEBP. Catalytic activities were enhanced by increasing the reaction temperature in the order: MTW$\mathrm{S} \approx \mathrm{MTW}-\mathrm{S} 1 \gg \mathrm{MTW}-\mathrm{L} 1>\mathrm{MTW}-\mathrm{L} \approx \mathrm{MTW}-\mathrm{L} 2$. The activities for the MTW zeolites increased rapidly from 250 to $300-350^{\circ} \mathrm{C}$; however, they were saturated at higher temperatures. MTW-S had higher activities than MTW-L; however, no significant change of activity occurred due to dealumination. On the other hand, the activity was enhanced by the dealumination of MTW-L by EDTA. The catalytic activity of MTW-L was enhanced due to deep dealumination with steaming and refluxing in $1 \mathrm{M}$ hydrochloric acid; however, it was less compared to that of MTW-L1.

The MTW zeolites had the higher selectivity for $4,4^{\prime}$-DEBP than the MOR and MFI zeolites. The selectivities for 4,4'-

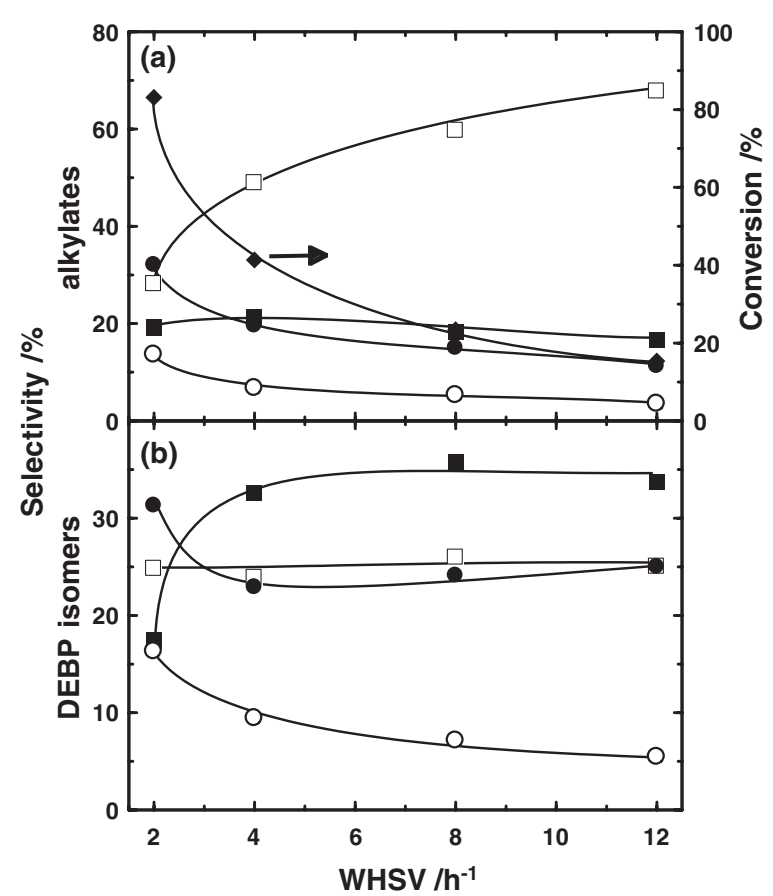

Fig. 11. The influences of WHSV on the ethylation of BP over MTW-S1. (a): Conversion of BP and selectivity for ethylates. (b) Selectivity for DEBP isomers. Reaction conditions: temperature, $250^{\circ} \mathrm{C}$; feed, 1:5:5.5 (BP:EtOH:CH (molar ratio)); WHSV, $8 / \mathrm{h}$. Data were taken at $6 \mathrm{~h}$ after starting. Legend: (a) $\square$ : EBP; $\mathbf{\square}$ : DEBP; ๑: TriEBP; $\bigcirc$ : TetraEBP. (b) $\square:$ 4,4'-DEBP; $\square$ : 3,4'-DEBP; $\bigcirc: 3,3^{\prime}$ DEBP; : $2, x^{\prime}$-DEBP.

DEBP over MTW-S, MTW-S1, MTW-L1, and MTW-L2 at $250{ }^{\circ} \mathrm{C}$ were nearly the same, and MTW-L had the lowest selectivity for 4,4'-DEBP. The selectivity for 4,4'-DEBP over MTW-S, MTW-S1, and MTW-L1 decreased with the increase in reaction temperature.

The decrease in the selectivity for $4,4^{\prime}$-DEBP was accompanied by an increase in the selectivity for $3,3^{\prime}$ - and $3,4^{\prime}$-DEBP isomers. Thermodynamically stable products easily formed at higher temperatures as $350{ }^{\circ} \mathrm{C}$. The bulky DEBP isomers, $2, x^{\prime}$-DEBP isomers formed predominantly at lower temperatures, and their formation decreased at higher temperatures. Another reason for the decrease of $4,4^{\prime}$-DEBP was its preferential consumption to higher ethylates.

Influences of WHSV and Time-on-Stream. Figure 11 shows the influence of weight hourly space velocity (WHSV) on the selectivity for DEBP isomers over MTW-S1 at $250{ }^{\circ} \mathrm{C}$. The conversion of BP and the selectivity for $4,4^{\prime}$-DEBP decreased with an increase in WHSV. The selectivity for $3,3^{\prime}-$ and 2, $x^{\prime}$-DEBP decreased; however, the selectivity for $3,4^{\prime}$ DEBP remained constant. These results show that an increase in WHSV, i.e., the decrease in contact time, caused a decrease in the formation of thermodynamically more stable isomers. The isomerization of $4,4^{\prime}$ - and $2, x^{\prime}$-DEBP decreased with the increase in WHSV.

Figure 12 shows the influence of time-on-stream (TOS) in the ethylation of BP over MTW-S1 at $250{ }^{\circ} \mathrm{C}$. The catalytic activity decreased with an increase in TOS which is most likely due to the deactivation of the active site. The selectivities 
for $4,4^{\prime}$ - and $3,4^{\prime}$-DEBP increased slightly during the reaction period; however, the selectivity for $2, x^{\prime}$-DEBP was rapidly decreased. The selectivity for 3,3'-DEBP was almost constant during the reaction. The increase in the selectivity for $4,4^{\prime}$ and 3,4'-DEBP and the corresponding decrease in those for

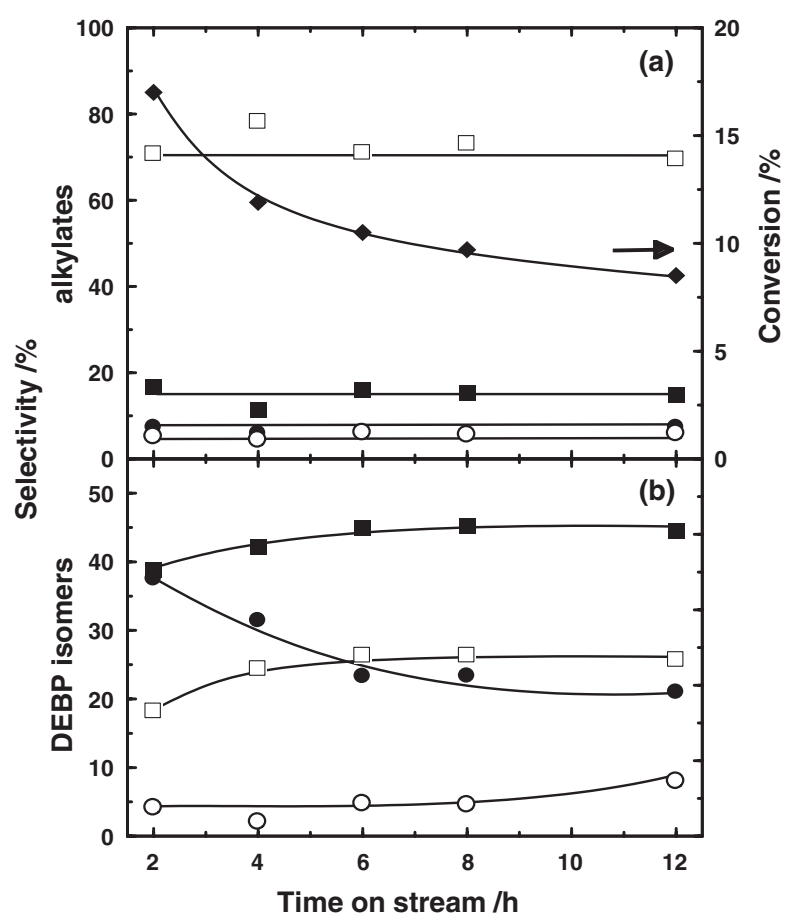

Fig. 12. The influences of time on stream on catalytic activity and product selectivities in the ethylation of BP over MTW-S1. (a) Selectivity for alkylates. (b) Selectivity for DEBP isomers. Reaction conditions: temperature, 250 ${ }^{\circ} \mathrm{C}$; feed, 1:5:5.5 (BP:EtOH:CH molar ratio); WHSV, 8/h. Legend: (a) $\square$ : EBP; $\mathbf{\square}$ : DEBP; $\bullet$ : TriEBP; $\bigcirc$ : TetraEBP. (b) $\square:$ 4,4'-DEBP; $\square: 3,4^{\prime}$-DEBP; $\bigcirc: 3,3^{\prime}$-DEBP; $\bullet: 2, x^{\prime}$ DEBP.
$2, x^{\prime}$-DEBP are due to the decrease in non-shape selective reaction at the external acid sites because of the coke deposition. Similar features were observed for the other MTW zeolites.

Molecular Fitting of Products of the Ethylation of BP in the Zeolites. The shape selectivity achieved by zeolites in catalytic conversion is governed by several factors, among which pore diameters of the zeolite as well as the size and the shape of the molecules. The relative rates of diffusion of the reactants, particle size, products, and intermediate (transition state) also play dominant roles.

Molecular dimensions of EBP and DEBP isomers are shown in Table 2. Energetically favorable conformation shows that 4,4'-DEBP (diameter $0.52 \mathrm{~nm}$ ) is the least bulky among DEBP isomers, and 3,4'-DEBP $(0.57 \mathrm{~nm})$ and $3,3^{\prime}$-DEBP $(0.64 \mathrm{~nm})$ are bulkier than 4,4'-DEBP. 4,4'-DEBP can easily diffuse in the MTW zeolite (pore diameter: $0.59 \mathrm{~nm}$ ). However, 3,3'and $3,4^{\prime}$-DEBP are the more stable among their isomers based on the total energies of energetically favorable conformations.

We used principal isomers formed in the ethylation of $\mathrm{BP}$, i.e., BP; 2-, 3-, and 4-EBP; and 2,4-, 2,4'-, 3,3'-, 3,4'-, and $4,4^{\prime}$-DEBP to determine the influence of bulkiness of molecules in MTW, MOR, and MFI channels. MTW and MOR zeolites have 12-membered (12-MR) straight channels with diameters of $0.56 \mathrm{~nm} \times 0.56 \mathrm{~nm}$ and $0.65 \mathrm{~nm} \times 0.70 \mathrm{~nm}$, respectively. The MFI zeolite has two types of 10 -membered (10-MR) channels with diameter $0.51 \mathrm{~nm} \times 0.55 \mathrm{~nm}$ (straight) and $0.56 \mathrm{~nm} \times 0.53 \mathrm{~nm}$ (zigzag). The straight channel was used for the calculations.

The dimension of the zeolites and DEBP isomers plays a crucial role in the ethylation of BP over zeolites. The zeolites with a pore diameter of 0.55 to $0.76 \mathrm{~nm}$ should be able to sieve $\mathrm{BP}, \mathrm{EBP}$, and DEBP isomers, particularly, 4,4'-, 3,4'-, and $3,3^{\prime}$-DEBP. Figure 13 (upper) shows the molecular graphics (MG) pictures of 3,4'-, 3,3'-, and 4,4'-DEBP isomers (CPK model) inside the MTW channels (cross section of the 12-MR). The diffusion of $4,4^{\prime}$-DEBP through MTW channels is easier than that of $3,4^{\prime}-$ and 3,3'-DEBP (Table 5). However, the

\section{4,4'-DEBP}
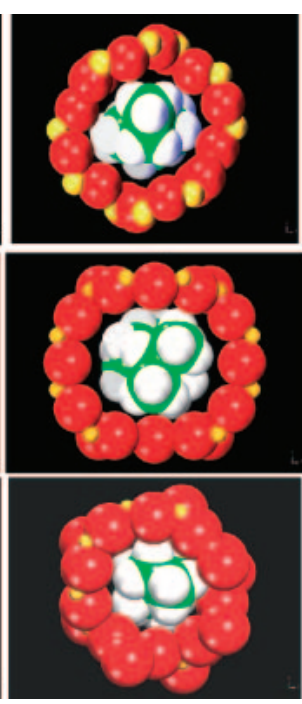

3,4'-DEBP
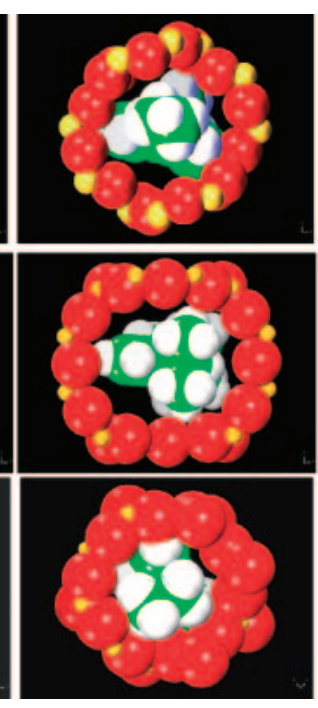

\section{3,3'-DEBP}
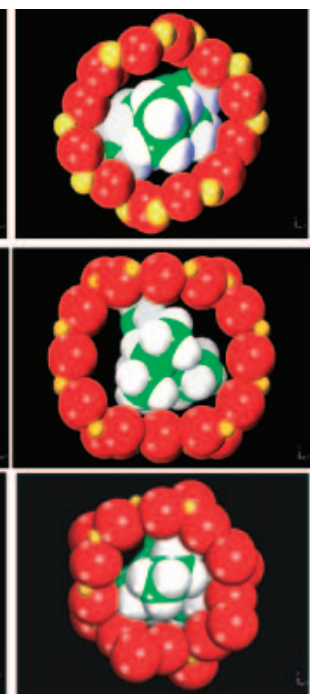

Fig. 13. The MG picture shows the fitting of DEBP isomers (CPK model) inside MTW, MOR, and MFI channels (cross-section of the 10 and 12-MR). Hydrogen atoms are white, carbon atoms are green, oxygen atoms are red and silicon atoms are yellow. 
Table 5. Diffusional Energy Barriers of DEBP Isomers over MTW, MOR, and MFI Zeolites

\begin{tabular}{lccc}
\hline & \multicolumn{3}{c}{ Diffusion energy barrier $/ \mathrm{kcal} \mathrm{mol}^{-1}$} \\
\cline { 2 - 4 } DEBP & MTW & MOR & MFI \\
\hline $2,4^{\prime}-$ & 30.5 & 7.9 & 119.1 \\
$2,4-$ & 55.0 & 13.0 & 181.5 \\
$3,3^{\prime}-$ & 45.7 & 3.7 & 123.7 \\
$3,4^{\prime}-$ & 14.7 & 2.8 & 51.2 \\
$4,4^{\prime}-$ & 3.6 & 2.3 & 21.1 \\
\hline
\end{tabular}

MTW channels are a little too large to achieve highly shape selective formation of 4,4'-DEBP. Figure 13 (middle) shows the MG pictures of these DEBP isomers inside the MOR channels (cross section of the 12-MR). All three isomers can accommodate well in MOR channels. However, no DEBP isomers can fit in MFI channels as shown in Fig. 13 (bottom). From these molecular graphics, we conclude that $4,4^{\prime}$-DEBP diffuses in the MTW channels more easily than 3,4'- and 3,3'-DEBP does, whereas MOR channels can allow the rapid diffusion of all DEBP isomers.

Diffusion of DEBP Isomers inside the Zeolites. It is difficult to generalize experimentally the diffusion characteristics of 4,4'-DEBP molecules inside zeolites. However, it is relatively easy to calculate the diffusion energy profiles from the interaction energies and to know the relative rates of diffusion through the channels of molecular sieves. The calculation of diffusion of DEBP isomers, such as 2,4-, 2,4'-, 3,3'-, 3,4'-, and 4,4'-DEBP, was carried out over MTW, MOR, and MFI zeolites. The molecules pass several maxima in the diffusion through a unit-cell. The typical diffusion energy profile for 4,4'-DEBP over the MTW zeolite is shown in Fig. 14, and it shows one minimum at $2 / 3$ of the unit cell, two maxima at the center of the unit-cell and another at the $1 / 3$ of the unit-cell. The diffusion energy for DEBP isomers are shown in Table 5. The diffusion barriers over the MTW zeolites decrease in the order: $3,3^{\prime}->3,4^{\prime}->4,4^{\prime}$-DEBP. The diffusion barriers of all EBP isomers in the MOR channels are lower than those of the MTW zeolites; however, DEBP isomers have much higher diffusion barriers in the MFI channels. These modeling results suggest that the MTW zeolite is the best candidate for the selective formation of 4,4-DEBP in the ethylation of BP.

Mechanistic Aspects of the Ethylation of BP over the MTW Zeolites. In the acid catalysis by zeolites, the reactant's fate and the product's formation probability are determined by molecular size and configurations of pores and channels, and only a reactant molecule whose dimension is less than the pore size can enter into the channels and react at the catalytic site. In addition, only molecules that can diffuse out through the channels will appear in the product. Therefore, the fitting of the reactants and products to the channels of the zeolites is the important keys for highly shape-selective catalysis. We previously found that the isopropylation of BP over the MOR zeolite gave selectively 4,4'-diisopropylbiphenyl $\left(4,4^{\prime}\right.$-DIPB $){ }^{1-5}$ However, no selective formation of $4,4^{\prime}$-DEBP was observed in the ethylation of BP. ${ }^{6-9}$ These differences are due to the fitting of the DIPB and DEBP isomers inside their channels. Only the slimmest $4,4^{\prime}$-DIPB can fit inside

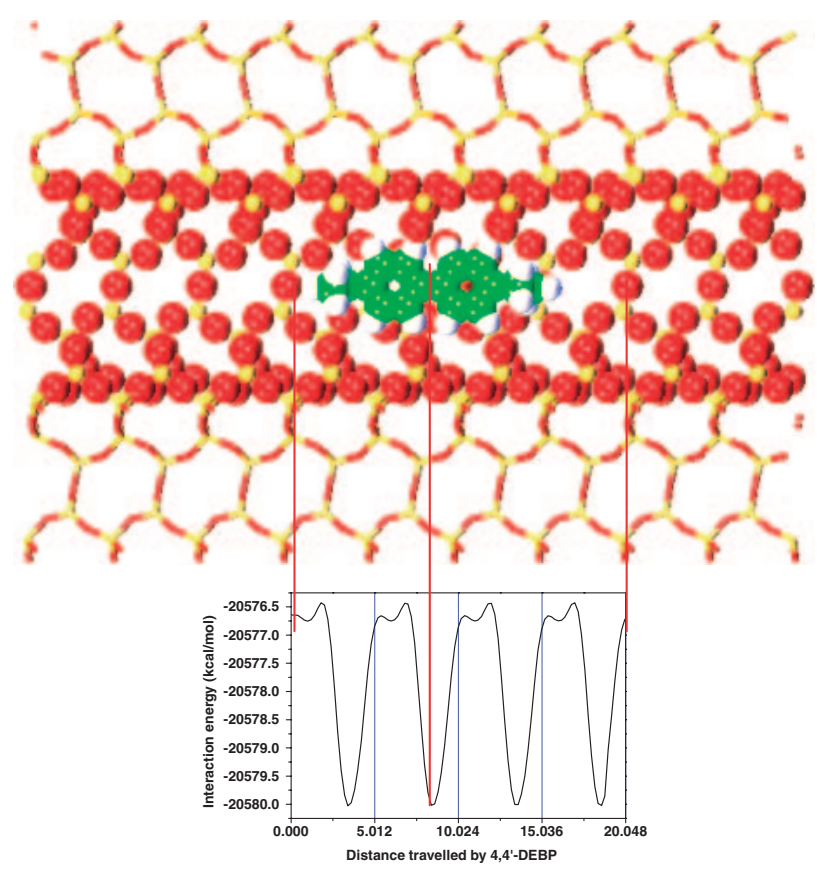

Fig. 14. Typical diffusion profile of the $4,4^{\prime}$-DEBP isomers in the 12-membered channels of MTW channel. Graph denotes the distance traveled by the 4,4'-DEBP isomer along the " $b$ " axis of the MTW channel vs interaction energies of $4,4^{\prime}$-DEBP and MTW channel.

the MOR channels in the isopropylation of BP. However, the MOR channels can accommodate all of the DEBP isomers, and are too wide for the selective formation of 4,4-DEBP. On the other hand, the MFI channels are too small for all of DEBP isomers to fit in them and diffuse out from them.

We are interested in the ethylation of BP over the MTW zeolites, which has two-dimensional twelve-membered channels and smaller pore mouth than the MOR zeolites, ${ }^{16}$ because the MTW channels are expected to exclude the formation of bulkier DEBP isomers and to form selectively 4,4' -DEBP. Experimentally, original MTW zeolites (MTW-S and MTW-L) did not have high activity and the selectivity for 4,4'-DEBP; however, the dealumination of the MTW zeolites enhanced the selectivity for $4,4^{\prime}$-DEBP because the dealumination reduced the number of choked pores due to coke-formation during the reaction. The best selectivity for 4,4'-DEBP of the MTW zeolites was round $30-40 \%$ among DEBP isomers although it is much higher than that of the MOR zeolites. The selectivity (42\%) for 4,4'-DEBP of MTW-L2 at $300^{\circ} \mathrm{C}$ was much higher than the equilibrium value of $4,4^{\prime}$-DEBP estimated from experiments $\left(11 \%\right.$ at $200{ }^{\circ} \mathrm{C}^{12}$ and $12 \%$ at $300{ }^{\circ} \mathrm{C}$ (Table 1)). This value is the most plausible selectivity for the MTW structure. These results show that $4,4^{\prime}$-DEBP is preferentially formed due to the steric interaction of reactants and products with the acidic sites in the MTW channels. There are two possible mechanisms for low selectivity for 4,4'-DEBP: A: The MTW channels are too loose for the selective formation of DEBP isomers, particularly $4,4^{\prime}$-DEBP.

B: The MTW channels are too tight for the ethylation of BP.

If the mechanism A is involved in the reaction, the catalytic features resemble to the case of the MOR zeolties. ${ }^{6-9}$ All of the 
isomers can fit inside the channels and diffuse out. The transition state to form 4,4'-DEBP should be favored over other transition states even inside wide MTW channels to result in the shape selective formation of $4,4^{\prime}$-DEBP. However, further ethylation of DEBP isomers occurs inside the channels, and in particular, 4,4'-DEBP also disappear by the further ethylation to higher ethylates. The formation of higher ethylates occurs inside the channels as well as the external acid sites.

If the catalysis occurs by the mechanism B, the shape-selective formation of $4,4^{\prime}$-DEBP occurs at the acid sites near the pore mouth because the pores are too small for the ethylation of BP. The steric restrictions at the pore mouth are less compared to the deep acid sites inside the pores, and result in lower shape-selectivity. The formation of higher ethylates occurred on the external acid sites. Currently, we are studying the relationships between the bulk and encapsulated products in liquid-phase ethylation of BP to elucidate the mechanisms of the shape-selective catalysis over the MTW zeolites. ${ }^{26}$

Molecular modeling on the diffusion of products in the MTW channels suggests that 4,4'-DEBP isomer can diffuse the easiest among DEBP isomers, and the formation of $4,4^{\prime}$ DEBP is the most favorable. However, the MTW channels are too wide for selective formation of $4,4^{\prime}$-DEBP based on a comparison between experimental results and molecular modeling. 4,4'-DEBP and the other isomers easily diffuse inside the MOR channel; however, they cannot in the MFI channels.

We would like to remind what shape-selective catalysis by a zeolite is and how much selectivity is requested for the shapeselective catalysis. The shape-selective catalysis by zeolites is not controlled thermodynamically, but controlled by steric restriction by the environment inside the channels. Shape-selectivity occurs when the transition state leads to the least bulky isomer in the restricted space inside the zeolites, although it is possible that another mechanism occurs, which is controlled by the rapid diffusion of the least bulky isomers from the zeolites. We can say that the shape-selective catalysis occurs if the selectivity for the least bulky isomer is reasonably higher than its concentration in a thermodynamical equilibrium for either mechanism. In other words, the MTW zeolites have the shape-selective characteristics towards the ethylation of BP. The MOR zeolite also has the shape-selective characteristics because its channels allows for the further ethylation of 4,4'-DEBP, formed shape-selectively, from 4-EBP to higher ethylates. $^{6-9}$

\section{Conclusion}

The vapor-phase ethylation of BP was studied over zeolites (MTW, MOR, and MFI). The activities are in the order: MOR $>$ MTW $\gg$ MFI, and the selectivity for 4,4'-DEBP was in the order: MTW $\gg$ MOR $\approx$ MFI. The small sized MTW zeolite had higher activity than the large crystals; however, the selectivity for $4,4^{\prime}$-DEBP was in the reverse order because the external acid sites become covered in coke during the reaction. The dealumination of both MTW zeolites improve the catalytic activities and gave rise to higher selectivity for $4,4^{\prime}$-DEBP $(30-40 \%)$. The improvements of catalytic performance are due to the decrease in the amounts of coke because of the decrease in acid sites caused by the dealumina- tion. The selectivity for 4,4'-DEBP over the MTW zeolites means that MTW channels have the shape-selective characteristics. The restricted transition states mechanism should be operative to form $4,4^{\prime}$-DEBP as the predominant isomer; however, the other transition states to bulkier DEBP isomers may occur because of wide channels.

Molecular modeling of the diffusion of the products inside the MTW channels suggests that 4,4'-DEBP diffuses the easiest among DEBP isomers. However, $4,4^{\prime}$-DEBP and other isomers easily diffuse inside the MOR channel; however, they cannot in MFI channels. These results show that the formation of $4,4^{\prime}$-DEBP is the most favorable based on the diffusion and the restriction of transition state in the MTW channels although the selectivity for $4,4^{\prime}$-DEBP is much lower compared to that for $4,4^{\prime}$-DIPB in the isopropylation.

The selectivity for 4,4'-DEBP over the MTW zeolites were far from the selective synthesis of 4,4'-DEBP for practical applications although the MTW zeolite gave the best selectivity among the zeolites. It is important to elucidate what happens inside the channels of zeolites in order to improve the catalytic performances. We are now investigating these aspects, and will report the details in the near future.

A part of this work was financially supported by a Grantin-Aid for Scientific Research (B) No. 16310056, the Japan Society for the Promotion of Science (JSPS), and by Research Project under the Japan-Korea Basic Scientific Cooperation Program, JSPS and Korea Science and Engineering Foundation (KOSEF). S. A. R. Mulla and S. B. Waghmode thank to the JSPS for postdoctoral fellowship.

\section{References}

1 Y. Sugi, Y. Kubota, in Catalysis: Specialist Periodical Reports, The Royal Society of Chemistry, 1997, Vol. 13, p. 55.

2 Y. Sugi, Korean J. Chem. Eng. 2000, 17, 1.

3 Y. Sugi, Y. Kubota, T. Hanaoka, T. Matsuzaki, Catal. Surv. Jpn. 2001, 5, 43.

4 P. B. Venuto, Microporous Mater. 1994, 2, 297.

5 Y. Sugi, S. Tawada, T. Sugimura, Y. Kubota, T. Hanaoka, T. Matsuzaki, K. Nakajima, K. Kunimori, Appl. Catal., A 1999, 198, 251.

6 X. Tu, M. Matsumoto, T. Maeda, Y. Sugi, T. Matsuzaki, T. Hanaoka, Y. Kubota, J. H. Kim, Microporous Mater. 1995, 3, 593.

7 M. Matsumoto, X. Tu, T. Matsuzaki, T. Hanaoka, Y. Kubota, Y. Sugi, J.-H. Kim, K. Nakajima, K. Kunimori, Stud. Surf. Sci. Catal. 1997, 105, 1317.

8 K. Nakajima, T. Hanaoka, Y. Sugi, T. Matsuzaki, Y. Kubota, A. Igarashi, K. Kunimori, Shape Selective CatalysisChemical Synthesis and Hydrocarbon Processing, ACS Symposium Series, No. 738, 1999, pp. 260-270.

9 Y. Sugi, S. Tawada, T. Sugimura, Y. Imada, Y. Kubota, T. Hanaoka, T. Matsuzaki, Stud. Surf. Sci. Catal. 2001, 135, 4558.

10 G. Takeuchi, Y. Shimoura, T. Hara, Appl. Catal. A 1996, 137, 87.

11 G. Takeuchi, Y. Shimoura, Catal. Surv. Jpn. 1998, $2,77$.

12 J. Qiu, K. Komura, Y. Kubota, Y. Sugi, Bull. Chem. Soc. Jpn. 2005, 78, 1160.

13 High Performance Polynuclear Aromatics Materials, ed. by Polym. Soc. Jpn., Maruzen, Tokyo, 1990.

14 G. A. Olah, Friedel Crafts and Related Reactions, John 
Wiley \& Sons, New York, 1964, Vol. 2, part 2, pp. 659-784.

15 Handbook of Green Chemistry and Technology, ed. by J. Clark, D. Macquarrie, Blackwell Sci., Oxford, 2002.

16 C. Baerlocher, W. M. Meier, D. H. Olson, Atlas of Zeolite Framework Types, 5th ed., Elsevier, Amsterdam, 2001, http:// www.iza-structure.org/databases/.

17 E. J. Rosinski, M. K. Rubin, U.S. Patent 3832 449, 1974.

18 S. Ernst, P. A. Jacobs, J. A. Matens, J. Weitkamp, Zeolites 1987, 7, 458.

19 M. J. Frisch, G. W. Trucks, H. B. Schlegel, G. E. Scuseria, M. A. Robb, J. R. Cheeseman, J. A. Montgomery, Jr., T. Vreven, K. N. Kudin, J. C. Burant, J. M. Millam, S. S. Iyengar, J. Tomasi, V. Barone, B. Mennucci, M. Cossi, G. Scalmani, N. Rega, G. A. Petersson, H. Nakatsuji, M. Hada, M. Ehara, K. Toyota, R. Fukuda, J. Hasegawa, M. Ishida, T. Nakajima, Y. Honda, O. Kitao, H. Nakai, M. Klene, X. Li, J. E. Knox, H. P. Hratchian, J. B. Cross, V. Bakken, C. Adamo, J. Jaramillo, R. Gomperts, R. E. Stratmann, O. Yazyev, A. J. Austin, R. Cammi, C. Pomelli, J. W. Ochterski, P. Y. Ayala, K. Morokuma, G. A. Voth, P. Salvador, J. J. Dannenberg, V. G. Zakrzewski, S. Dapprich, A. D. Daniels, M. C. Strain, O. Farkas, D. K. Malick, A. D. Rabuck, K. Raghavachari, J. B. Foresman, J. V. Ortiz, Q. Cui,
A. G. Baboul, S. Clifford, J. Cioslowski, B. B. Stefanov, G. Liu, A. Liashenko, P. Piskorz, I. Komaromi, R. L. Martin, D. J. Fox, T. Keith, M. A. Al-Laham, C. Y. Peng, A. Nanayakkara, M. Challacombe, P. M. W. Gill, B. Johnson, W. Chen, M. W. Wong, C. Gonzalez, J. A. Pople, Gaussian 03, Revision 1, Gaussian, Inc., Wallingford CT, 2004.

20 a) R. C. Deka, R. Vetrivel, J. Catal. 1988, 174, 88. b) S. B. Waghmode, P. Bharathi, S. Sivasanker, R. Vetrivel. Microporous Mesoporous Mater. 2000, 38, 433, and reference therein.

21 A. Alberti, P. Davoli, G. Vezzalini, Z. Kristallogr. 1986, $175,249$.

22 H. van Koningsveld, H. van Bekkum, J. C. Jansen, Acta Crystallogr., Sect. B 1987, 43, 127.

23 C. A. Fyfe, H. Gies, G. T. Kokotailo, B. Marler, D. E. Cox, J. Phys. Chem. 1990, 94, 3718.

24 A. T. Hagler, S. Lifson, P. Dauber, J. Am. Chem. Soc. 1979, 101, 5122.

25 P. Dauber-Osguthorpe, V. A. Roberts, D. J. Osguthorpe, J. Wolff, M. Genest, A. T. Hagler, Proteins: Struct., Funct., Genet. 1988, 4, 31 .

26 Unpublished results. 